\title{
Thermal, dielectric and mechanical study of poly(vinyl chloride)/olive pomace composites
}

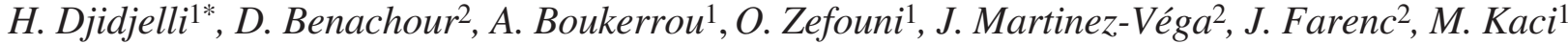 \\ ${ }^{1}$ Laboratoire des Matériaux Organiques, University A. Mira of Bejaia, Bejaia, Algeria \\ 2University Ferhat Abbas, Setif, Algeria \\ ${ }^{3}$ Laboratoire de Génie Electrique, (UMR-CNRS 5003) Université Paul Sabatier, Toulouse, France
}

Received 3 September 2007; accepted in revised form 25 November 2007

\begin{abstract}
Composites from PVC and chemically treated olive pomace have been prepared. The effect of the incorporation of virgin and benzylated olive pomace in the poly(vinyl chloride) matrix on dielectric, mechanical and thermal stability properties, of /olive pomace composites was studied.

The mechanical properties of the benzylated composites were improved. Furthermore, the thermal characterization of the different samples carried out by thermogravimetric analysis revealed an increase in the onset temperatures of decomposition for the treated composites.

The dielectric investigation indicated that the samples containing olive pomace treated with the benzyl chloride can be used in electrical applications as insulators.
\end{abstract}

Keywords: polymer composites, mechanical properties, thermal stability, dielectric properties

\section{Introduction}

Olive pomace is an industrial byproduct of the olive oil production process that is obtained by squeezing the olive pulp without any chemical treatment. By water addition, three phases occur: oil, water and pomace. Chemically, the vigin olive pomace contains cellulose, hemicellulose and lignin, and cannot be processed as plastics due to both the high degree of cristallinity of the cellulose and the three-dimensional network.

In the last decade, wood-derived fillers have become more accepted in the thermoplastic industry. Polymer composites filled with natural lignocellulosic fibers have attracted the attention of many researchers and technologists [1-5]. Both polymer matrices and natural filler systems have been widely investigated [6-10]. As a matter of fact, Oksman and Lindberg [11] as well as the team of Liao [12] studied the mechanical behavior of composites based on polyethylene and wood flour samples [11, 12]. On the other hand, Zaini et al. [13], Nitz et al. [14], and Kaci et al. [15, 16] investigated the mechanical behavior of polypropylene/wood flour composites. Some authors examined also the mechanical behavior of PS/PEHD/ wood flour [17]. The electrical properties of SBR/ PS blend and chemically treated wood flour have been investigated by the team of Mansour [18].

On the contrary, the research work dealing with $\mathrm{PVC} /$ wood flour composites is rather scarce. Although, some papers have been reported in literature including those of Matuana and Mengeloglu [19], Pedro et al. [20] devoted to a comparative study of the mechanical behavior of $\mathrm{PVC} / \mathrm{CaCO}_{3}$ with PVC/agalmatolithe, while Sain et al. investigated the filled PE/WF, PVC/WF et PP/WF formulations [21].

*Corresponding author, e-mail: hocdjidjidj@yahoo.fr

(C) BME-PT and GTE 
On the other hand, there are only a few works reported in the literature on olive pomace rejects and their uses in many applications involving mainly the production of thermal energy, fertilizer as well as food for animals [22-25].

In the present work, Algerian olive pomace was used as filler to reinforce polyvinylchloride composites. Thus decrease in amount of PVC in use and can accelerate its degradation. Every year, during the season of transformation of olive to oil, thousands tons of olive pomace are rejected to nature or incinerated causing environmental pollution. The recovery of this renewable waste may have a double positive impact, economic and ecological.

To solve the problem of the processability, it is proposed to plasticize the olive pomace by chemical treatment with benzyl chloride, this treatment have been already done by Hartman et al. [26], Lu and Zhang [27] and the results have proved that the polysaccharide-based natural polymers can be plasticized and processed. Therefore better processability of the composite materials and higher interfacial adhesion between the polymer and the filler are expected.

\section{Experimental part}

\subsection{Materials}

All the PVC-Olive pomace composite formulations used in this work were prepared based on PVC type $4000 \mathrm{M}$ produced by the Algerian Company named 'Entreprise Nationale des Industries Pétrochimiques-ENIP' in Skikda on the Eastern Coast of Algeria. The polymer has the following physical characteristics: $K_{\text {value }}, 67$; powder density, $0.56 \mathrm{~g} \cdot \mathrm{ml}^{-1}$; thermal stability, $60 \mathrm{~min}$ at $180^{\circ} \mathrm{C}$ according to DIN 53381 part 1 . The additives used in the preparation of the various formulations were di(2-ethyl-hexyl phthalate) (DEHP) as a plasticizer produced by ENIP SKIKDA, Algeria, with a vis- cosity ranging from 80 to $85 \mathrm{mPa} \cdot \mathrm{s}$, a molecular weight of $390 \mathrm{~g} \cdot \mathrm{mol}^{-1}$, a boiling temperature of $233^{\circ} \mathrm{C}$, a thermal stabilizer system based on $\mathrm{Ba}-\mathrm{Zn}$ type LANKRO-MARK LZB325 produced by Akros Chemicals Ltd. U.K. and epoxidized Soya bean oil (ESBO) as co-stabilizer and a lubricant. The blend obtained with PVC resin and the different additives (dry blend) were used to prepare the composites formulations. Olive pomace was used as filler having a length of around $100 \mu \mathrm{m}$.

\subsection{Chemical treatment of olive pomace by benzylation}

The Algerian olive pomace was subjected to several pretreatments, i. e. washing with hot water to eliminate pulp, drying under ambient conditions for $24 \mathrm{~h}$ then in a drying oven at $80^{\circ} \mathrm{C}$ for $24 \mathrm{~h}$, crushing and finally sifting to obtain a flour of size lower than $100 \mu \mathrm{m}$ which was dried under vacuum at $80^{\circ} \mathrm{C}$ for 12 hours.

After being pre-swelled by $18 \% \mathrm{NaOH}$ for $1 \mathrm{~h}$, the powder was transferred into a flask containing phase transfer catalyst and benzyl chloride.

The reaction was carried out under vigorous stirring at $120^{\circ} \mathrm{C}$ for $4 \mathrm{~h}$ at reflux. The products were purified through washing for several times with distilled water to remove inorganic salts, and with ethanol to remove residues of benzyl chloride. Finally, the treated flour was dried again under vacuum at $60^{\circ} \mathrm{C}$ for $72 \mathrm{~h}$ to be used as filler in composite matrix.

Five formulations of PVC with the olive pomace were prepared, the reference F0 only made of PVC without olive pomace, two formulations with PVC and the untreated olive pomace at 5 and $25 \%$ by weight noted by F5 and F25 and finally two formulations PVC with the treated olive pomace with benzyl chloride at 5 and $25 \%$ by weight noted by F5B and F25B. The mass composition of the several formulations was reported in Table 1.

Table 1. Mass composition of the various PVC formulations

\begin{tabular}{|c|c|c|c|c|c|c|c|}
\hline \multirow{2}{*}{ Components } & \multicolumn{7}{|c|}{ Formulations } \\
\hline & F0 & F5 & F15 & F25 & F5B & F15B & F25B \\
\hline PVC resin & 100 & 100 & 100 & 100 & 100 & 100 & 100 \\
\hline (DEHP) & 30 & 30 & 30 & 30 & 30 & 30 & 30 \\
\hline $\mathrm{Ba}-\mathrm{Zn}$ & 0.2 & 0.2 & 0.2 & 0.2 & 0.2 & 0.2 & 0.2 \\
\hline ESBO & 0.5 & 0.5 & 0.5 & 0.5 & 0.5 & 0.5 & 0.5 \\
\hline Virgin olive pomace & 0 & 5 & 15 & 25 & 0 & 0 & 0 \\
\hline Benzylated olive pomace & 0 & 0 & 0 & 0 & 5 & 15 & 25 \\
\hline
\end{tabular}




\subsection{Sample preparation}

Blends based on PVC powder, various additives, and olive pomace before and after treatment were placed in a high-speed twin steel-wall mixer and processed at a speed of $3000 \mathrm{rpm}$ at $50^{\circ} \mathrm{C}$, below the glass transition temperature of PVC to avoid gelification.

The different PVC formulations obtained were used to prepare preblended films by calendaring process at $160^{\circ} \mathrm{C}$ with a residence time of $8 \mathrm{~min}$. The films obtained were placed in an aluminum mold which was placed between two steel platens. A Fontume Holland hydraulic oil heated press with a nominal maximum pressure level up to $250 \mathrm{kN}$ was used for compression molding. The press platens were maintained at $170^{\circ} \mathrm{C}$ for $3 \mathrm{~min}$. The plates obtained are $2 \mathrm{~mm}$ thick and they will be used for testing. The sample preparation was carried out in the laboratory of CABEL 'Cablerie Electrique' located in Algiers (Algeria).

\subsection{Spectroscopic analysis}

FTIR measurements were carried out on a SPECTRUM 100 Fourier-transform infrared spectrophotometer at a resolution of $4 \mathrm{~cm}^{-1}$ with an accumulation of 100 scans for each spectrum. The infrared spectra were recorded in absorbance units in the $4000-400 \mathrm{~cm}^{-1}$ range. FTIR spectra were measured in $\mathrm{KBr}$ pellets containing $1 \%$ finely ground samples.

\subsection{Mechanical properties}

Five samples of each test were used to determine tensile and impact properties. The tensile test was performed on a ZWICK/ROEL Z 2.5 tensile testing apparatus at a cross-head speed of $10 \mathrm{~mm} / \mathrm{min}$, according to ISO 527-1 procedure. The size of the specimen was $75 \times 13 \times 4 \mathrm{~mm}$.

\subsection{Thermal stability}

For thermal stability analysis, the decomposition rates were measured by a SETARAM TGT DTA 92 thermogravimetric apparatus. A sample of initial mass of 15 to $20 \mathrm{mg}$ was introduced into a platinum crucible; the sample mass (TG) variation was then measured as a function of temperature (or time), and the rates of mass loss (DTG) were determined by using a thermobalance under an inert argon atmosphere up to $600^{\circ} \mathrm{C}$, at a heating rate of

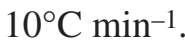

The onset of decomposition temperature corresponds to the inflexion point of the TG curve.

\subsection{Dielectric properties}

Permittivity and dielectric loss measurements were measured by using a dielectric spectrometer, type DEA2970. The apparatus allows the measurements of various dielectric properties over a large range of temperatures and frequencies at heating rate of $2{ }^{\circ} \mathrm{C} / \mathrm{min}$.

\section{Results and discussion}

\subsection{Characterization of olive pomace}

FTIR spectra of olive pomace before and after benzylation are illustrated in Figure 1. It can be observed clearly that the chemical structure of benzylated olive pomace is quite different from that of the untreated one. The intensity of the absorption band of hydroxyl groups which appear at about $3500 \mathrm{~cm}^{-1}$ decreases after benzylation process as a result of etherification. This broad band at $3500 \mathrm{~cm}^{-1}$ cannot be assigned to the presence of water in the samples and, possibly in $\mathrm{KBr}$ because both the samples and $\mathrm{KBr}$, before the FTIR analysis, were subjected to heat treatment in an oven at $80^{\circ} \mathrm{C}$ until the weight of the sample was constant. Results obtained from infrared spectra prove that the hydroxyl concentration decreases with the chemical treatment because the hydroxyl groups are substituted by the benzyl groups. This in addition, a reduction in the absorption band which appears at $1730 \mathrm{~cm}^{-1}$ corresponding to the carbonyl groups is well detected for benzylated olive pomace sample compared to the untreated sample. This

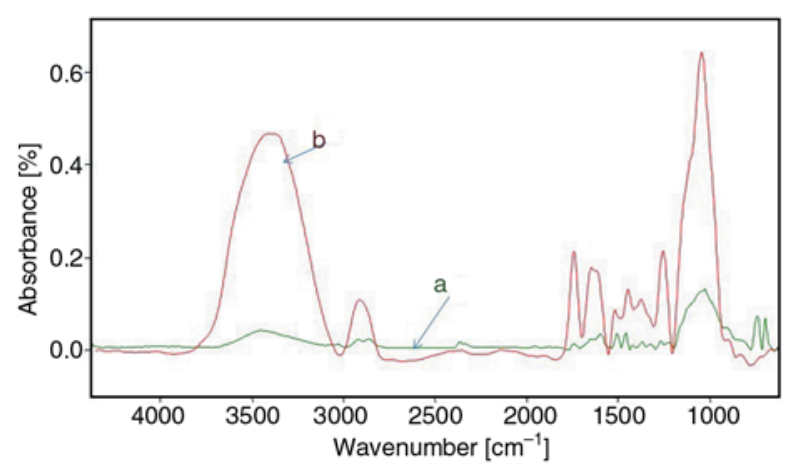

Figure1. FTIR spectra of a: untreated olive pomace and b: benzylated olive pomace 
reduction can be attributed to the partial extraction of the lignin and the hemicellulose which contain these groups by the chemical treatment [21]. The appearance of a new absorption band characteristic of the phenyl groups located approximately at $736-695 \mathrm{~cm}^{-1}$. This band is nonexistent in FTIR spectra of the untreated olive pomace, that indicates that the reaction of the monosubstitution of the sodium ions by the benzyl groups occurred.

Instead, the degree of advance of this reaction can be evaluated by measuring the weight gain of the sample at the end of the reaction. This weight gain is attributed to the fact that the benzyl groups are heavier than the hydrogen groups. Indeed, it is obtained 30\% weight gain of the sample (degree of benzylation of pomace).

\subsection{Characterization of composites PVC/olive pomace}

\subsubsection{Mechanical properties}

The effect of the olive pomace incorporation on the mechanical properties of $\mathrm{PVC} / \mathrm{untreated}$ olive pomace composites was examined. Figure 2, 3 and 4 show the mechanical behaviours of different PVC/ olive pomace composites before and after treatment.

Generally, the incorporation of untreated olive pomace results in a very similar trend of decrease in both elongation and strain at break. In terms of tensile properties, the decrease of elongation and strength at break was probably caused by a number of factors, including moisture pick-up, poor disper-

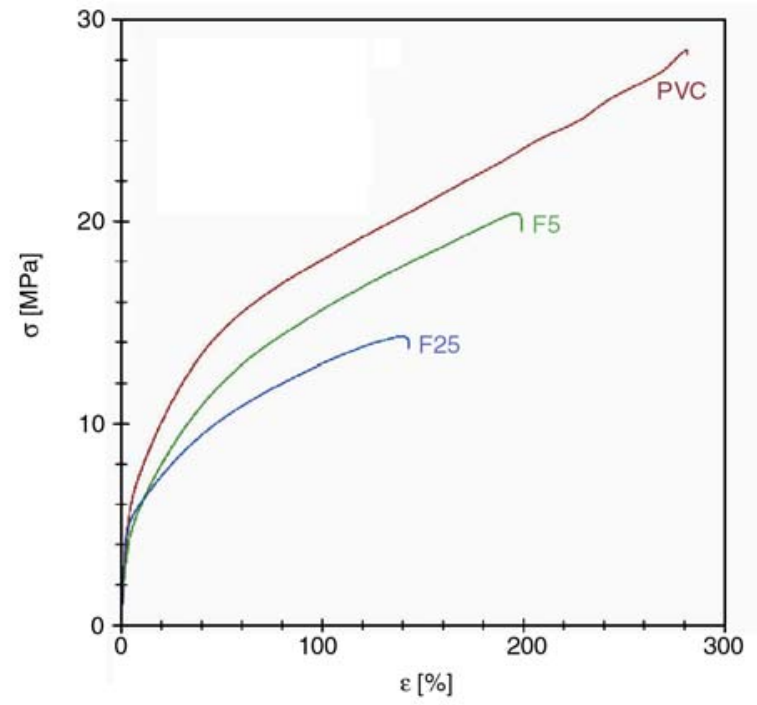

Figure 2. Tensile properties of virgin $\mathrm{PVC}$ and PVC/untreated olive pomace composites sion of olive pomace in the matrix and increase of interfacial defects in debonding between polymer and olive pomace. The results obtained were in a good correlation with those found by Sombatsompop and Chaochanchaikul with the samples of PVC/sawdust composites [28]. The tensile properties of highly viscous thermoplastics, rubber materials or plasticized PVC depend on several factors, such as dispersion of fiber, increase in stress concentration at fiber ends and amount of air retained in the composite during mixing [19]. However it can be noticed an increase in both elongation and strength at break for the composite samples prepared with the modified fillers with benzyl chloride. It was found a value of elongation at break of

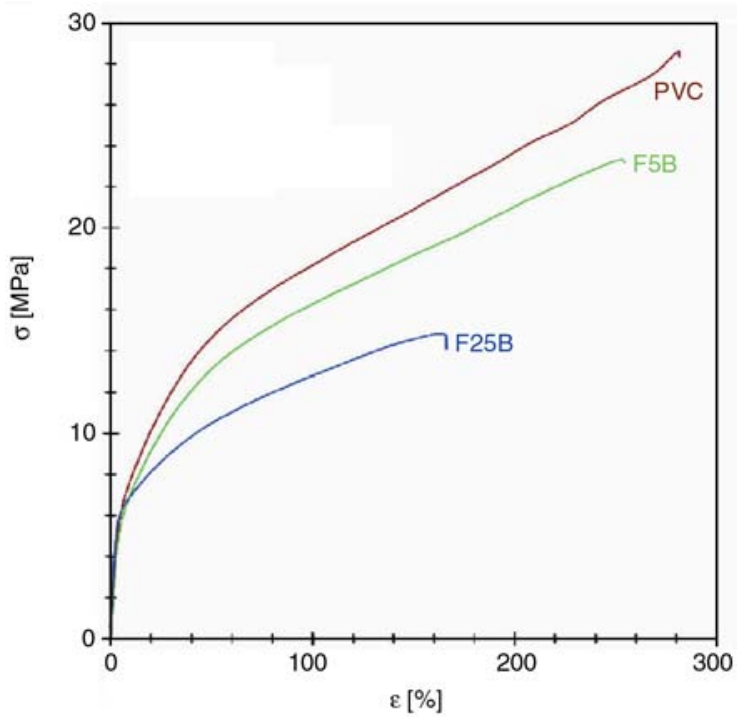

Figure 3. Tensile properties of virgin PVC and PVC/benzylated olive pomace composites

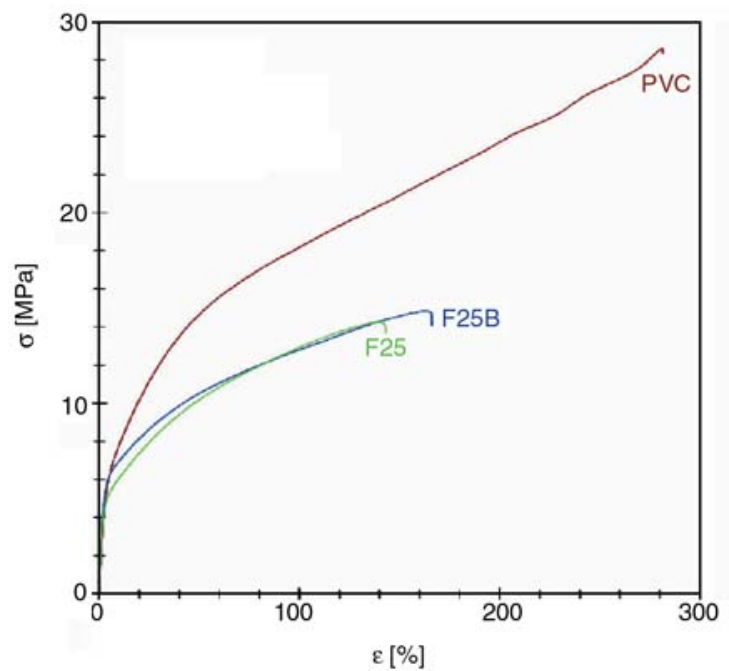

Figure 4. Tensile properties of virgin PVC, PVC/untreated olive pomace and $\mathrm{PVC} /$ benzylated olive pomace composites 
almost $141 \%$ for the F25 and $166 \%$ for the F25B. The improvement of both elongation and strength at beak of benzylated composites is due to the thermoplastic character of the benzylated flour of olive pomace and consequently the good interfacial adhesion matrix/filler.

Generally, the tensile test shows clearly that the olive pomace has undergone a plasticization after treatment with benzyl chloride as reported by many authors. The olive pomace has been converted into a thermoplastic material after benzylation and acquired thermoforming ability leading to improvement in the mechanical properties of the composites compared to the untreated ones.

It can be noticed that the Young modulus is influenced by the addition of olive residue and benzylation. The value passes from 71 for F0 to $101 \mathrm{MPa}$ for F25. The incorporation of $25 \%$ wt. of untreated olive pomace in the PVC matrix increase the Young modulus by $40 \%$, it provides to the composite higher rigidity because of the rigid filler character. On the other hand, the addition of $25 \%$ wt. of olive pomace treated by benzyl chloride, no change in the modulus was observed when compared to that of unloaded PVC matrix. Generally, the tensile test shows clearly that the flour of olive residue has undergone a plasticization after treatment with benzyl chloride.

\subsubsection{Thermal properties}

The different composites were subjected to thermogravimetric analysis in argon atmosphere to understand their thermal behaviour. TG thermograms are shown in Figure 5 and the results are summarized in Table 2.

The data of Table 2 shows clearly that the incorporation of the treated olive pomace or the untreated one in the matrix PVC permits a gain in the onset temperature of the decomposition. In other words, the sample of the loaded PVC present a onset temperature of decomposition higher than that of F0, this is verified for the samples loaded with the vir-

Table 2. The effect of the chemical treatment and content of olive pomace on the onset temperature in TGA

\begin{tabular}{|l|c|}
\hline \multicolumn{1}{|c|}{ Samples } & Onset degradation temperature $\left[{ }^{\circ} \mathbf{C}\right]$ \\
\hline F0 & 239.2 \\
\hline F5 & 280.3 \\
\hline F5B & 286.9 \\
\hline F25 & 241.0 \\
\hline F25B & 253.8 \\
\hline
\end{tabular}

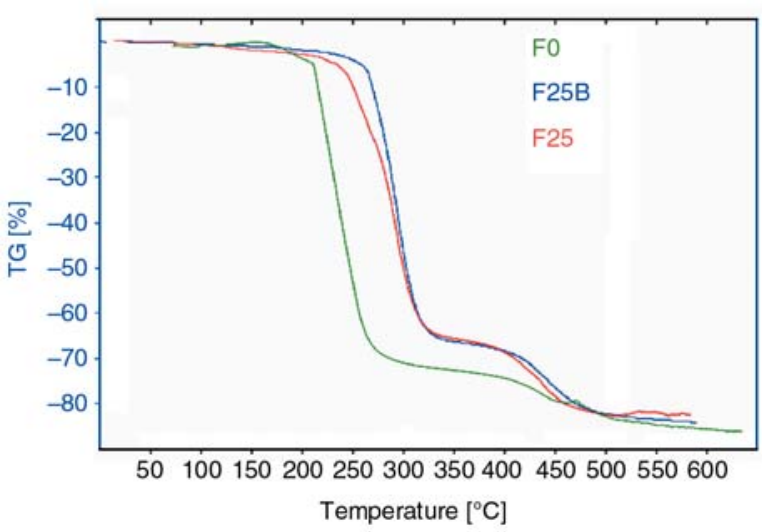

Figure 5. TG thermograms of virgin $\mathrm{PVC}$ and PVC/untreated and benzylated olive pomace composites

gin or the treated olive pomace. For example, a gain of $14^{\circ} \mathrm{C}$ by F25B. Moreover, the effect of the chemical treatment on the onset temperature of the decomposition, a gain of $12^{\circ} \mathrm{C}$ is recorded by F25B in comparison to F25 sample. Concerning the weight loss recorded in the first stage of the decomposition, we can clearly see that the treated sample has almost the same rate of weight loss and lower than the sample of reference F0. This result is expected considering the treated samples which have undergone an extraction of hemicellulose that is degraded thermally at this temperature range. On the other hand, the samples loaded with the virgin olive pomace present a loss of weigh clearly superior to that of $\mathrm{F} 0$ witch can be explained by the degradation of hemicellulose and PVC at this temperature range.

\subsubsection{Dielectric properties}

The permittivity and dielectric loss factor values for PVC loaded with different concentrations of untreated olive pomace and those treated with benzyl chloride were measured at fixed frequency $(100 \mathrm{~Hz})$ and at temperatures ranging from -50 to $130^{\circ} \mathrm{C}$.

The effect of temperature on both permittivity and dielectric loss at fixed frequency $(100 \mathrm{~Hz})$ for all the samples except F25, are illustrated graphically in Figures 6 and 7. From this figures it is clear that both values increase by increasing temperature, and this increase is slight at temperature ranging from -60 to $0^{\circ} \mathrm{C}$, medium between 0 and $40^{\circ} \mathrm{C}$ and more pronounced after $70^{\circ} \mathrm{C}$. For the samples F0, F15, F15B and F25 it is preferable to use them at temperatures not more than $70^{\circ} \mathrm{C}$, e.g., the values of the 


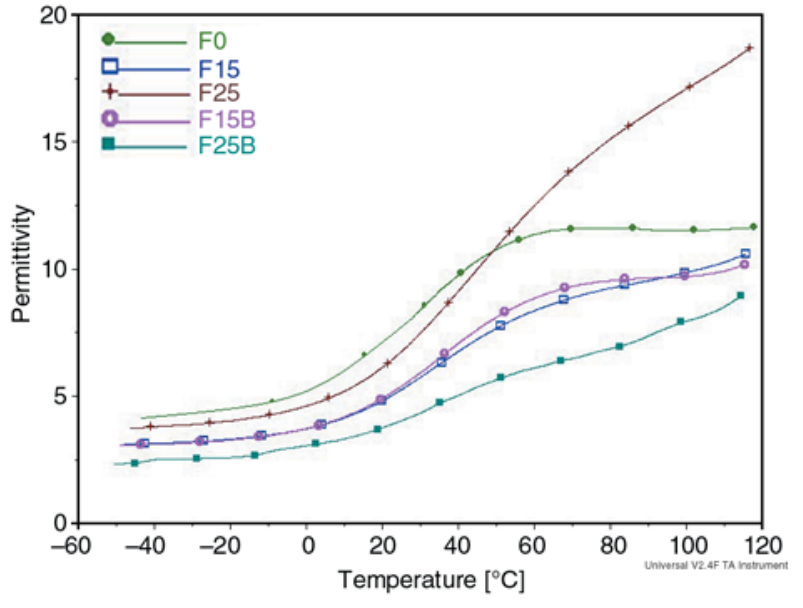

Figure 6. The variation of permittivity versus temperature at fixed frequency $(100 \mathrm{~Hz})$ for the different composites

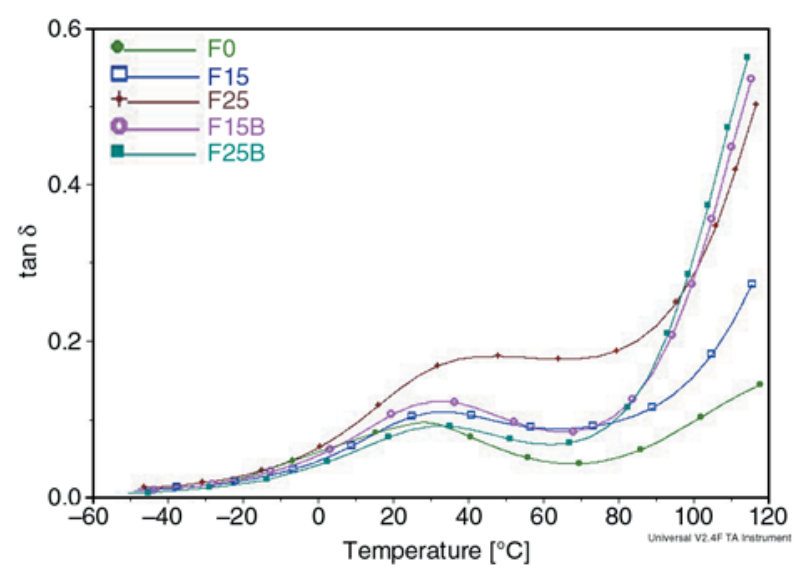

Figure 7. The variation of loss factor versus temperature at fixed frequency $(100 \mathrm{~Hz})$ for the different composites

dielectric loss rise for the samples of F15B from 0.796 at $70^{\circ} \mathrm{C}$ to 1.537 at $100^{\circ} \mathrm{C}$.

For F25 the sample which contains a sizeable concentration of olive pomace, the increase is pronounced much starting from $0^{\circ} \mathrm{C}$ and it is not advised to use it in the field of the electric insulation, e.g. the values of the dielectric loss rise for the samples of $\mathrm{F} 25$ from 0.298 at $0^{\circ} \mathrm{C}$ to 2.478 at $70^{\circ} \mathrm{C}$. On the other hand with the chemical treatment by benzylation this sample F25B records less important dielectric loss and can be used in insulation purposes.

\section{Conclusions}

The results of the infrared spectroscopy indicate clearly that the reaction of the monosubstitution of the sodium ions by the benzyl groups was occurred in the structure of the olive pomace.
Also, the incorporation of the treated olive pomace in the PVC matrix improves both elongation and strength at beak of benzylated composites; this is due to the thermoplastic character of the benzylated flour of olive pomace and consequently the good interfacial adhesion matrix/filler.

The effect of the chemical treatment on the onset temperature of the decomposition, a gain of $12^{\circ} \mathrm{C}$ is recorded by F25B in comparison to F25 sample.

On the other hand with the chemical treatment by benzylation this sample F25B records less important dielectric loss and can be used in insulation purposes.

\section{References}

[1] Belgacem M. N., Gandini A.: The surface modification of cellulose fibres for use as reinforcing elements in composite materials. Composite Interfaces, 12, 4175 (2005).

[2] Marcovich N. E., Aranguren M. I., Reboredo M. M.: Modified woodflour as thermoset fillers Part I. Effect of the chemical modification and percentage of filler on the mechanical properties. Polymer, 42, 815-825 (2001).

[3] Nunez A. J., Kenny J. M., Reboredo M. M.: Thermal and dynamic mechanical characterization of polypropylene-woodflour composites. Polymer Engineering and Science, 42, 733-742 (2002).

[4] Marcovich N. E., Reboredo M. M., Aranguren M. I.: Lignocellulosic materials and unsaturated polyester matrix composites: Interfacial modifications. Composite Interfaces, 12, 3-24 (2005).

[5] Belgacem M. N.: Surface modification of cellulose fibres. Polimeros: Ciencia e Tecnologia, 15, 114-121 (2005).

[6] Ferreira F. C., Curvelo A. A. S., Mattoso L. H. C.: Preparation and characterization of benzylated sisal fibers. Journal of Applied Polymer Science, 89, 2957 2965 (2003).

[7] Guinez D., Jasso C., Fuentes F., Navarro F., Davalos F., Ramos J.: Chemical treatments on sisal fibers to produce composite materials with polyethylene and polyestirene. in 'Abstracts of $8^{\text {th }}$ International Symposium on Polymers for Advanced Technologies. Budapest, Hungary' 140 (2005).

[8] Lu X., Zhang M. Q., Rong M. Z., Shi G., Yang G. C.: Self-reinforced melt processable composites of sisal. Composite Science and Technology, 63, 177-186 (2003).

[9] Lu X., Zhang M. Q., Rong M. Z., Shi G., Yang G. C.: All-plant fiber composites. I: Unidirectional sisal fiber reinforced benzylated wood. Polymer Composites, 23, 624-633 (2002). 
[10] Zhang M. Q., Rong M. Z., Lu X.: Fully biodegradable natural fiber composites from renewable resources: All-plant fiber composites. Composites Science and Technology, 65, 2514-2525 (2005).

[11] Oksman K., Lindberg H.: Influence of thermoplastic elastomers on adhesion in polyethylene-wood flour composites. Journal of Applied Polymer Science, 68, 1845-1855 (1998).

[12] Liao B., Huang Y., Cong G.: Influence of modified wood fibers on the mechanical properties of wood fiber-reinforced polyethylene. Journal of Applied Polymer Science, 66, 1561-1568 (1997).

[13] Zaini M. J., Fuad M. Y. A., Ismail Z., Mansor M. S., Mustafah J.: The effect of filler content and size on the mechanical properties of polypropylene/oil palm wood flour composites. Polymer International, 40, 51-55 (1996).

[14] Nitz H., Reichert P., Römling H., Mülhaupt R.: Influence of compatibilizers on the surface hardness, water uptake and the mechanical properties of poly(propylene) wood flour composites prepared by reactive extrusion. Macromolecular Materials and Engineering, 276-277, 51-58 (2000).

[15] Kaci M., Cimmino S., Silvestre C., Duraccio D., Benhamida A., Zaidi L.: Ethylene butyl acrylate glycidyl methacrylate terpolymer as an interfacial agent for isotactic poly(propylene)/wood flour composites. Macromolecular Materials and Engineering, 291, 869-876 (2006).

[16] Kaci M., Zaidi L., Benhamida A., Cimmino S., Duraccio D.: Ethylene n-butyl acrylate glycidyl methacrylate terpolymer as compatibilizer for isotactic polypropylene/wood flour composites. Czasopismo Techniczne, 103, 251-256 (2006).

[17] Xu B., Simonsen J., Rochefort W. E.: Creep resistance of wood-filled polystyrene/high-density polyethylene blends. Journal of Applied Polymer Science, 79, 418425 (2001)

[18] Mansour S. H., Asaad J. N., Abd-El-Messieh S. L.: Synthesis and characterization of brominated polyester composites. Journal of Applied Polymer Science, 102, 1356-1365 (2006).
[19] Matuana L. M., Mengeloglu F.: Microcellular foaming of impact-modified rigid PVC/wood-flour composites. Journal of Vinyl and Additive Technology, 7, 67-75 (2001).

[20] Pedro B. M. A., Monteiro E. C., Dweck J.: PVC and agalmatolite composite characterization. Polymer Testing, 20, 269-273 (2001).

[21] Sain M. M., Balatinecz J., Law S.: Creep fatigue in engineered wood fiber and plastic compositions. Journal of Applied Polymer Science, 77, 260-268 (2000).

[22] Chen M-J., Meister J. J., Gunnels D. W., Gardner D. J. J.: A process for coupling wood to thermoplastics using graft copolymers. Advances in Polymer Technology, 14, 97-109 (1995).

[23] Sébe G., Brook M. A.: Hydrophobization of wood surfaces: covalent grafting of silicone polymers. Wood Science and Technology, 35, 269-282 (2001).

[24] Matuana L. M., Belatinez J. J., Sodhi R. N. S., Park C. B.: Surface characterization of esterified cellulosic fibers by XPS and FTIR spectroscopy. Wood Science and Technology, 35, 191-201 (2001).

[25] Nunez A. J., Kenny J. M., Reboredo M. A., Aranguren M. I., Marcovich N. E.: Thermal and dynamic mechanical characterization of polypropylene-woodflour composites. Polymer Engineerig and Science, 42, 733-742 (2002).

[26] Hartman J., Albertsson A-C., Sjöberg J.: Surface-and bulk-modified galactoglucomannan hemicellulose films and film laminates for versatile oxygen barriers. Journal of Biomacromolecules, 7, 1983 (2006).

[27] Lu Y., Zhang L.: Morphology and mechanical properties of semi-interpenetrating polymer networks from polyurethane and benzyl konjac glucomannan. Polymer, 43, 3979-3986 (2002).

[28] Sombatsompop N., Chaochanchaikul K.: Effect of moisture content on mechanical properties, thermal and structural stability and extrudate texture of poly(vinyl chloride)/wood sawdust composites. Polymer International, 53, 1210-1218 (2004). 